\title{
The Relationship between Time Pressure and Burnout Syndrome: A Cross-Sectional Survey among Jordanian Nurses
}

\author{
Muhammad W. Darawad1, Hani Nawafleh², Mahmoud Maharmeh", \\ Ayman M. Hamdan-Mansour1,3, Saleh N. Azzeghaiby ${ }^{3}$ \\ ${ }^{1}$ Faculty of Nursing, The University of Jordan, Amman, Jordan \\ ${ }^{2}$ Faculty of Nursing, Al-Hussein Bin Talal University, Maan, Jordan \\ ${ }^{3}$ Al-Farabi College for Dentistry and Nursing, Al-Farabi College, Riyadh, KSA \\ Email: m.darawad@ju.edu.jo, hnawafleh@hotmail.com, m.maharmeh@ju.edu.jo, a.mansour@ju.edu.jo, \\ talal5656@yahoo.com
}

Received 22 October 2014; revised 29 November 2014; accepted 10 December 2014

Copyright (C) 2015 by authors and Scientific Research Publishing Inc.

This work is licensed under the Creative Commons Attribution International License (CC BY).

http://creativecommons.org/licenses/by/4.0/

(c) (i) Open Access

\begin{abstract}
Burnout among nurses is well documented in literature. Precursors of burnout such as time pressure need further study for better understanding. In Jordan literature, studies regarding time pressure and burnout among Jordanian nurses are scarce. This study aimed to 1) evaluate the relationship between time pressure and burnout, and 2) identify participants' characteristics that may have relationship with time pressure and burnout. A descriptive correlational design was utilized using a self-reported cross-sectional survey to collect data from 175 Jordanian nurses. Participants reported high level of time pressure $(24.8$ out of 126$)$ and burnout (72.9 out of 126). Time pressure was correlated with emotional exhaustion and depersonalization $(r=0.561,0.491$, $P<0.01$, respectively). Burnout was highest on the emotional exhaustion (72\%) compared to $53.9 \%$ for depersonalization and $\mathbf{4 9 . 2 \%}$ for personal achievement. Depersonalization showed the most frequent correlation with participants' characteristics. Burnout was found to be common among Jordanian nurses, and time pressure is a precursor of this phenomenon, giving rise to the consequences on both patients' and nurses' health. Healthcare administrators have to modify the nursing work environment to be less stressful and more appealing to overcome the causes of nurses' burnout.
\end{abstract}

\section{Keywords}

Time Pressure, Burnout, Work Environment, Nurses, Jordan 


\section{Introduction}

Nurses' turnover rates have increased significantly leading to a challenge facing healthcare institutions and are growing annually. For instance, the American Health Care Association [1] reported that the turnover rate among the hospital nurses in the United States (US) has increased to $45 \%$ in all nursing facilities. Such high rates were reported in other countries including 19.9\% in Canada [2], and 36.6\% in Jordan [3]. Moreover, the 5-year nursing turnover in Taiwan was reported to be 50\% [4]. These high turnover rates constitute a major contributor to the problem of nursing shortage.

In order to understand the phenomenon of high turnover rates among nurses, it is important to investigate the nursing work environment, which has a negative impact not only on nurses' retention, but also on the profession's ability to recruit new nurses, and without addressing this environment, all strategies for the resolution of the high turnover rates among nurses will not be effective [5]. Alhussami and colleagues [6] reported a significant relationship between quality of work and nurses' turnover intention. However, nursing work environment is known by the heavy workload, high stress, numerous responsibilities, critical decisions, and limited authority [7]. Such an environment, beside other personal and professional issues, was found to be the main cause of nurses' burnout [8] [9]. Such phenomenon was found to be global among nurses, with no country-level effect for nursing work environment on nurses' burnout [10].

Burnout was first described by Freudenberger [11], and was defined as a lack of energy and emotions for work [12], especially among professionals who work in a direct relationship with the beneficiaries of their service [13]. Further, burnout was described as a psychological syndrome, in which burned out workers feel that they are emotionally exhausted, depersonalized, with a sense of reduced personal achievement [12]. This means that burned out nurses have inadequate energy and emotions to meet the demands of both patients and workplace. Moreover, they may suffer from anxiety due to incomplete healthcare tasks and inability to fulfill their assigned workload [9].

The syndrome of burnout continues its effect among nurses by decreasing their job satisfaction and increasing their turnover intention [14] [15], and by causing psychologic symptoms, low morale, and alcohol and drug abuse [16]. However, patients are also affected by this syndrome where reports indicate a correlation between nurses' burnout and increased rates of urinary tract and surgical sites infection [17], and decreased patient satisfaction with nursing care [16]. At the organizational level, burnout was found to increase absenteeism, turnover, and errors [16], work place bullying and incivility [18], and the cost of compensating for the high rate of illnessrelated absenteeism among nurses [19].

Many causes are yet not studied that may contribute to nurses' burnout, and identifying potential risk factors is necessary. For instance, time pressure among nurses is defined as the stress caused by lack of time for completing the required nursing tasks, which can be attributed to the multiple nursing roles and limited time for patient care, and has many consequences on patients through decreasing nurses' ability to discover patients' needs, make clinical judgments, and perform nursing interventions [20], in addition to increasing the likelihood of errors [21]. Consequently, time pressure decreased patients' perception of the quality of nursing care in terms of assurance, responsiveness, and accountability [22]. Concurrently, time pressure was found to affect nurses' health both physically and psychologically [23]. The relationship between time pressure and burnout was established by Teng and colleagues [9] who found time pressure to have a significant positive relationship with emotional exhaustion $(r=0.38)$ and inverse relationship with personal achievement $(r=-0.12)$.

Jordan, as a small developing country, suffers from the problem of high nurses' turnover, which was reported to be $36.6 \%$ and contributes to the problem of nursing shortage in Jordan [3] including both organizational and professional turnover. Moreover, Jordanian nurses were found to have high rates of turnover intention [6] [24]. Such a problem is intensified in smaller countries due to the lack of resources, producing a serious issue that influences the viability of the healthcare system [25].

The healthcare system in Jordan has tremendously grown during the last two decades, making Jordan "a referral medical station for clients in the Middle East, especially the Arab Gulf countries” [26] (p. 83). The surveys regarding patients' satisfaction with nursing care in Jordan pointed out to the low rates of satisfaction compared to other countries [27], which made the problem of nurses' turnover both a workforce and public health issue. Indeed, there have been limited published research studies regarding burnout among nurses as a precursor for nurses' turnover in Jordan. Such studies could have potential benefits for nurses and nursing profession, patients, and the healthcare organizations. Also, it can serve as a basis for other studies in different 
countries concerning burnout among nurses to build on its results. The purposes of this study are to: 1) evaluate the relationship between time pressure and the components of burnout, and 2) identify participants' demographic or professional characteristics that may have relationship with time pressure and burnout.

\section{Methodology}

Design: A descriptive correlational design was utilized using a self-reported cross-sectional survey.

Setting and Sampling: Data were collected from three large hospitals in Jordan (two governmental and one teaching). To be eligible, participant had to be a registered or an assistant nurse and had been working in nursing for at least three months. After obtaining the approval from the participating hospitals, nurses were interviewed and those who accepted participation were asked to fill out the questionnaire package. Out of 250 invited nurses, 175 accepted participation and returned the completed questionnaires (response rate 70\%).

Instrument: Three parts were included in the questionnaire package of this study. The first part included participants' demographic characteristics including their age, gender, unit (intensive care unit/ floor), education, total years of experience in the current unit and in nursing, and position (assistant nurse, registered nurse, administrator). The second section measured participants' perceived time pressure using five items adopted from the work of Putrevu and Ratchford [28]. For the purpose of this study, the modification made by Teng and colleagues [9] to include the phrase "at work" was adopted. The response options ranged from 1 "never" to 7 "always", with a total range of 5 - 35 where higher scores indicate more perceived time pressure. Putrevu and Ratchford [28] reported a good internal consistency for this instrument $(\alpha=0.90)$, and Teng and colleagues [9] reported a Cronbach's alpha of 0.96 among nurses. The current study found Cronbach's alpha to be 0.81 .

The third section used the Maslach Burnout Inventory-Human Service Scale (MBIHSS) [12], which is widely used to measure burnout in service environments including nursing. The original scale contains 22 items, but the modified version by Teng and colleagues [9] was used, which contains only 18 items as four items are not applicable for the purpose of this study (nursing environment). A 7-point Likert scale was utilized ranging from 1 "a few times a year/very mild" to 7 "every day/very strong", with a range of $18-126$ and higher scores indicate more burnout. The items of the MBIHSS are further classified into three subscales including emotional exhaustion (7 items), depersonalization (4 items), and personal achievement (7 reversely-stated items). The validity of this 18-item version was established using confirmatory factor analysis [9], and the Cronbach's alpha values were $0.92,0.84$, and 0.86 , respectively. For the current study, Cronbach's alpha values were found to be 0.88 , $0.71,0.89$, respectively.

Ethical considerations: The Research and Ethics Committee at the participating hospitals granted the ethical approval to conduct this study. Nurses were informed regarding the voluntary and anonymous participation (no personal identification were recorded). The researchers have assigned identification numbers for participants instead of using their names for accessing research data, and the access was limited to research team. Also, detailed information regarding the aims of the study and participants' rights were provided for participants through the questionnaire cover letter. Upon their agreement, participants were given a closed envelope that contained a copy of the cover letter and the instrument of the study. Also, they were notified that returning the filled out package is an implied consent.

Data collection: After obtaining the ethical approval for this study, trained data collectors met the head nurses at the participating hospitals to seek their permission to interview nurses in their units after full explanation of the study aims and procedure. Then, data collectors personally interviewed nurses on duty, over frequent visits on different shifts, and invited them to voluntarily participate in the study. Upon their agreement, participating nurses were given the study package, which contained a copy of the cover letter that explains the aims of the study, participants' rights, and instructions for completing and returning the package, along with the instrument of the study. Participants filled out the questionnaire during their break time and data collectors were available to receive the filled out questionnaires from them.

Data analysis: Descriptive statistics were utilized to describe participants' characteristics using means and standard deviations (continuous variables) and frequencies and percentages (categorical variables). Additionally, frequencies were used to identify areas of most time pressure and burnout among nurses through item analysis. To test the differences in nurses' reported time pressure and burnout subscales based on their categorical demographic characteristics, both independent $t$ test and Analysis of Variance (ANOVA) were used. Finally, Pearson correlation test was used to test the correlation among nurses' reported time pressure, burnout subscales, and 
participants' continuous demographic characteristics. The Statistical Package for the Social Sciences (SPSS Inc., Chicago, II, USA) was used to run all statistical tests, which were run at $\alpha=0.05$ significance level (2-tailed).

\section{Results}

\subsection{Sample Characteristics}

A total of 175 nurses participated in the current study, of whom 109 were female (62.3\%), 74 were single (55.4\%), 94 had bachelor degree (53.7\%), 96 were registered nurses (54.9\%), 108 working in a public hospital (61.7\%), and 106 in medical/surgical floors (60.6\%). Participants' mean age was 29.4 years $(\mathrm{SD}=6.3)$, their mean years of experience was 7.1 years in nursing $(\mathrm{SD}=5.8)$ and 4.9 years in their current organization $(\mathrm{SD}=$ 4.1). Detailed demographic characteristics are provided in Table 1.

\subsection{Time Pressure and Burnout}

As shown in Table 2, the total score of MBI was 72.9 out of 126 (SD $=13.9)$, with scores of the MBI subscales 35.3 out of $49(\mathrm{SD}=8.7)$ for emotional exhaustion, 15.1 out of $28(\mathrm{SD}=5.6)$ for depersonalization, and 24.1 out of 49 (SD = 7.7) for personal achievement. The mean for time pressure was reported to be 24.8 out of 35 (SD = 6.1). Examining the relationship between time pressure and the three components of burnout (Table 3) revealed that time pressure had a strong positive correlation with emotional exhaustion $(\mathrm{r}=0.561, \mathrm{P}<0.01)$ and depersonalization $(r=0.491, P<0.01)$. However, personal achievement relationship with time was not statistically significant $(\mathrm{r}=-0.139, \mathrm{P}=0.067)$.

Table 1. Sample demographic characteristics $(\mathrm{N}=175)$.

\begin{tabular}{|c|c|c|}
\hline Characteristics & Mean (SD) & n (\%) \\
\hline \multicolumn{3}{|l|}{ Gender } \\
\hline Male & & 66 (37.7) \\
\hline Female & & $109(62.3)$ \\
\hline \multicolumn{3}{|l|}{ Marital Status } \\
\hline Single & & $74(55.4)$ \\
\hline Married & & $93(40)$ \\
\hline Others & & $8(4.6)$ \\
\hline \multicolumn{3}{|l|}{ Hospital type } \\
\hline Teaching & & $67(38.3)$ \\
\hline Public & & $108(61.7)$ \\
\hline \multicolumn{3}{|l|}{ Education } \\
\hline Diploma & & 68 (38.9) \\
\hline Bachelor & & $94(53.7)$ \\
\hline Master & & $13(7.4)$ \\
\hline \multicolumn{3}{|l|}{ Position } \\
\hline Assistant nurse & & 64 (36.6) \\
\hline Registered nurse & & 96 (54.9) \\
\hline Administrative & & $15(8.6)$ \\
\hline \multicolumn{3}{|l|}{ Area } \\
\hline Unit & & 69 (39.4) \\
\hline Floor & & $106(60.6)$ \\
\hline Age & $29.4(6.3)$ & \\
\hline Nursing Experience & $7.1(5.8)$ & \\
\hline Organizational experience & $4.9(4.1)$ & \\
\hline
\end{tabular}


Table 2. Descriptive statistics for burnout and time pressure.

\begin{tabular}{|c|c|c|c|c|}
\hline Characteristics & $\alpha$ & Mean (SD) & Minimum & Maximum \\
\hline MBI: Total & 0.77 & $72.9(13.9)$ & 41 & 112 \\
\hline MBI: Emotional Exhaustion & 0.88 & $35.3(8.7)$ & 7 & 49 \\
\hline MBI: Depersonalization & 0.71 & $15.1(5.6)$ & 4 & 28 \\
\hline MBI: Personal Achievement & 0.89 & $24.1(7.7)$ & 9 & 42 \\
\hline Time Pressure & 0.81 & $24.8(6.1)$ & 10 & 35 \\
\hline
\end{tabular}

MBI: Maslach Burnout Inventory.

Table 3. Pearson correlations of maslach burnout inventory with time pressure and participants continuous demographics.

\begin{tabular}{|c|c|c|c|c|c|c|c|}
\hline & 1 & 2 & 3 & 4 & 5 & 6 & 7 \\
\hline MBI: Emotional Exhaustion & 1.00 & & & & & & \\
\hline MBI: Depersonalization & $0.453^{* *}$ & 1.00 & & & & & \\
\hline MBI: Personal Achievement & $-0.295^{* *}$ & 0.075 & 1.00 & & & & \\
\hline Time Pressure & $0.561^{* *}$ & $0.491^{* *}$ & -0.139 & 1.00 & & & \\
\hline Age & 0.077 & -0.110 & $-0.292^{* *}$ & 0.065 & 1.00 & & \\
\hline Nursing Experience & 0.114 & $-0.172^{*}$ & $-0.336^{* *}$ & 0.010 & $0.882^{* *}$ & 1.00 & \\
\hline Organizational Experience & 0.049 & $-0.223^{* *}$ & $-0.259^{* *}$ & -0.004 & $0.661^{* *}$ & $0.784^{* *}$ & 1.00 \\
\hline
\end{tabular}

${ }^{* *}$ Correlation is significant at $\alpha=0.01$ (2-tailed), ${ }^{*}$ Correlation is significant at $\alpha=0.05$ (2-tailed).

\subsection{Relationship of Time Pressure and Burnout with Participants' Characteristics}

To assess the correlation of participants' reported time pressure and burnout with their demographic and professional characteristics, Pearson correlation test was used for continuous variables (Table 3) and t-test and ANOVA for categorical variables (Table 4).

Results showed that emotional exhaustion had no significant correlation with any of the continuous variables, and that no difference based on any other categorical variables. On the other hand, depersonalization was found to be inversely correlated with duration of nursing experience $(r=-0.172, \mathrm{P}<0.05)$ and organizational experience $(r=-0.223, P<0.01)$. Also, depersonalization was found to be higher among nurses in teaching hospitals $(\mathrm{P}<0.01)$ and nurses who had Masters degree $(\mathrm{P}<0.01)$. Similarly, personal achievement was found to have significant inverse correlations with participants' age $(\mathrm{r}=-0.223, \mathrm{P}<0.01)$, duration of nursing experience $(\mathrm{r}=$ $-0.336, \mathrm{P}<0.01)$, and organizational experience $(\mathrm{r}=-0.259, \mathrm{P}<0.01)$. Also, personal achievement was found to be higher among male nurses $(\mathrm{P}<0.05)$ and nurses in teaching hospitals $(\mathrm{P}<0.01)$. Finally, time pressure did not have any correlation with continuous participants' characteristics, but found to be higher among nurses in teaching hospitals.

\section{Discussion}

The current study aimed to evaluate the relationship between time pressure and the components of burnout among Jordanian nurses, and to identify their demographic or professional characteristics that may have relationship with time pressure and burnout. Work is considered a significant life domain for nurses in that it adds to overall job satisfaction and enhances organizational commitment [29]. On the other hand, work environment can be annoyance and disturbance and may generate irritation, burnout, and many psychological outcomes.

The majority of the sampled nurses reported experiencing time pressure in their work environment (24.8 out of 35). This finding is in agreement with the results of previous studies [30] [31]. Also, the reported level of burnout was also high (72.9 out of 126), which supports the international trends that indicate the globality of this phenomenon. It was noteworthy that the highest of burnout was reported on the emotional exhaustion (72\%) 
Table 4. Analysis of study variables based on categorical participants' demographics.

\begin{tabular}{|c|c|c|c|c|}
\hline Variable & $\begin{array}{l}\text { MBI: Emotional } \\
\text { Exhaustion }\end{array}$ & MBI: Depersonalization & $\begin{array}{c}\text { MBI: Personal } \\
\text { Achievement }\end{array}$ & Time Pressure \\
\hline \multicolumn{5}{|l|}{ Gender } \\
\hline Male & 34.8 & 15.9 & $25.5^{*}$ & 25.4 \\
\hline Female & 35.6 & 14.6 & 23.2 & 24.4 \\
\hline \multicolumn{5}{|l|}{ Marital Status } \\
\hline Single & 35.1 & 15.7 & 24.5 & 25.1 \\
\hline Married & 35.4 & 14.7 & 23.9 & 24.7 \\
\hline Others & 38.3 & 14.3 & 19.5 & 22.3 \\
\hline \multicolumn{5}{|l|}{ Hospital Type } \\
\hline Public & 34.4 & $14.1^{* *}$ & $22.1^{* *}$ & $23.7^{* *}$ \\
\hline Teaching & 36.8 & 16.8 & 27.2 & 26.6 \\
\hline \multicolumn{5}{|l|}{ Education } \\
\hline Diploma & 36.3 & 14.0 & 22.5 & 24.1 \\
\hline Bachelor & 34.3 & 15.4 & 25.1 & 24.9 \\
\hline Master & 37.5 & $19.1^{* *}$ & 25.0 & 27.1 \\
\hline \multicolumn{5}{|l|}{ Position } \\
\hline Assistant Nurse & 35.2 & 15.9 & 25.3 & 25.5 \\
\hline Registered Nurse & 35.5 & 14.1 & 22.7 & 24.1 \\
\hline Administrative & 35.8 & 14.2 & 22.5 & 23.8 \\
\hline \multicolumn{5}{|l|}{ Area } \\
\hline Unit & 34.1 & 15.7 & 24.1 & 24.7 \\
\hline Floor & 36.1 & 14.7 & 24.0 & 24.9 \\
\hline
\end{tabular}

${ }^{* * *}$ Correlation is significant at $\alpha=0.01$ (2-tailed), ${ }^{*}$ Correlation is significant at $\alpha=0.05$ (2-tailed).

compared to $53.9 \%$ for depersonalization and $49.2 \%$ for personal achievement. This confirms the finding that emotional exhaustion to be the component of burnout syndrome [32].

Time pressure was identified as an important factor of nurses' burnout as the study results suggest that nurses' time pressure was significantly correlated with two components of burnout; emotional exhaustion and depersonalization. These results were consistent with the result found by Li and colleagues [10] who found time pressure to have a significant positive relationship with emotional exhaustion, however inverse relationship was found with personal achievement. Also, Bakker and colleagues [30] found that nurses who perceived time pressure more frequently experienced higher depersonalization. Their results showed that those physical and emotional demands might influence employees' attitudes toward their work, inspiring feelings such as depersonalization. In this regard, Julliann [33] mentioned that time pressure is considered as a changeable factor compared to other work-related factors in relation to burnout. Therefore, nurse managers and human resource management have to work hard on nurses' load to ensure that nurses can work in unstressful setting, and decrease nurses' time pressure, which will be reflected on both nurses and patient care.

Regarding the demographic variables, personal achievement was found to have significant inverse correlations with participants' age, duration of nursing experience, and organizational experience. However, emotional exhaustion did not correlate with those three demographics. This was totally opposite to what was found by Iglesias and colleagues [7]. Nurses' perspectives in both studies might be different, which needs further investigation in order to better understand such difference. 
Time pressure did not have any correlation with continuous participants' characteristics. Similar results were reported by Josefsson [23] among Swedish nurses. The reasons for such an interpretation have not been studied very thoroughly, however, those who burnout early in their careers is likely to quit their jobs more than other counterparts. The lack of significant difference between nurses in different hospital settings was noteworthy, and came in congruence with Hooper and colleagues [34] who reported no difference between nurses in terms of risk for burnout. Such finding confirms the stressful nursing work environment as precursor for nurses' burnout. Therefore, Nursing managers have to consider nurses' time pressure when assigning nursing schedules and job-related tasks [22].

The contribution of the present study is that the frequency of time pressure on nurses was related to their burnout. Previous studies have not suggested methods for lessening time pressure. Therefore, it was difficult to understand how perceived time pressure caused burnout. This study only measured the relationship of time pressure experienced by nurses in hospital settings with their burnout level. If nurses do not have enough time to care for their patients or to meet the family demands then they may face difficulties and conflicts either with their patients or with the family members. Time for bedside nursing care contributes to positive patient outcomes, however, time pressure significantly reduce patients' quality of care [35] [36].

The limited sample size and limited hospital number constituted a limitation for this study, for which future studies are recommended to include a larger sample size of nurses and hospitals at a national level. However, the results of this study, along with other studies, set the can be used as a baseline in order to better understand the phenomenon of burnout among Jordanian nurses, so that healthcare administrators can set better solutions. Also, the use of the cross-sectional design could not enable the causal relationship. Future studies are recommended to use the longitudinal design to overcome the effect of nursing rotation and shift changes. Finally, this study did not assess the effect of time pressure and burnout among nurses on their patients. Such study would be the first in Jordan, and will provide more insight of the effect of such phenomenon, and consequently will be more convincing to the healthcare administrator to modify the nursing work environment to be less stressful and more appealing.

\section{Conclusion}

This study explored the level of time pressure and burnout among Jordanian nurses, which were found to be high and consistent with those reported in the literature. Time pressure was found to be correlated with the components of burnout, but not with the participants' demographics. On the other hand, emotional exhaustion scored as the highest component of burnout, and personal achievement had the most correlation with participants' demographics. Healthcare administrators have the obligation to modify the nursing work environment to be less stressful and more appealing in order to overcome the causes of the phenomenon of nurses' burnout.

\section{References}

[1] American Health Care Association (2012) 2011 AHCA Staffing Survey Report. http://www.ahcancal.org/research_data/staffing/Documents/2011\%20Staffing\%20Survey\%20Report.pdf

[2] O’Brien-Pallas, L., Murphy, G., Shamian, J., Li, X. and Hayes, L. (2010) Impact and Determinants of Nurse Turnover: A Pan-Canadian Study. Journal of Nursing Management, 18, 1073-1086. http://dx.doi.org/10.1111/j.1365-2834.2010.01167.x

[3] Hayajneh, Y., AbuAlRub, R., Athamneh, A. and Almakhzoomy, I. (2009) Turnover Rate among Registered Nurses in Jordanian Hospitals: An Exploratory Study. International Journal of Nursing Practice, 15, 303-310. http://dx.doi.org/10.1111/j.1440-172X.2009.01758.x

[4] Shih, H., Chen, J., Lee, J., Yeh, M. and Tung, T. (2014) Determinants and Impact of Turnover Rate among Nursing Staff: The Exploratory Retrospective Follow-Up Study in Taiwan. Asia Life Sciences, 23, 175-185.

[5] Peterson, C.A. (2001) Nursing Shortage: Not a Simple Problem-No Easy Answers. Online Journal of Issues in Nursing, 6, 1 .

[6] Al-hussami, M., Darawad, M., Saleh, A. and Hayajneh, F. (2013) Predicting Nurses' Turnover Intentions by Demographic Characteristics, Perception of Health, Quality of Work, and Work Attitudes. International Journal of Nursing Practice, 20, 79-88. http://dx.doi.org/10.1111/ijn.12124

[7] Iglesias, M., Vallejo, R. and Fuentes, P. (2013) The Relationship between Experiential Avoidance and Burnout Syndrome in Critical Care Nurses: A Cross-Sectional Questionnaire Survey. International Journal of Nursing Studies, 47, 30-37. http://dx.doi.org/10.1016/j.ijnurstu.2009.06.014 
[8] Książek, I., Stefaniak, J., Stadnyk, M. and Książek, J. (2011) Burnout Syndrome in Surgical Oncology and General Surgery Nurses: A Cross-Sectional Study. European Journal Oncology Nursing, 15, 347-350. http://dx.doi.org/10.1016/j.ejon.2010.09.002

[9] Teng, C., Shyu, Y., Chiou, W., Fan, H. and Lam, S. (2010) Interactive Effects of Nurse-Experienced Time Pressure and Burnout on Patient Safety: A Cross-Sectional Survey. International Journal of Nursing Studies, 47, 1442-1450. http://dx.doi.org/10.1016/j.ijnurstu.2010.04.005

[10] Li, B., Bruyneel, L., Sermeus, W., Van den Heede, K., Matawie, K., Aiken, L., et al. (2013) Group-Level Impact of Work Environment Dimensions on Burnout Experiences among Nurses: A Multivariate Multilevel Probit Model. International Journal of Nursing Studies, 50, 281-291. http://dx.doi.org/10.1016/j.ijnurstu.2012.07.001

[11] Freudenberger, H. (1974) Staff Burnout. Journal of Social Issues, 30, 159-165. http://dx.doi.org/10.1111/j.1540-4560.1974.tb00706.x

[12] Maslach, C. and Jackson, S. (1984) Burnout in Organizational Settings. Applied Social Psychology Annual, 5, $133-153$.

[13] Oliver, C., Gonzales, S. and Martinez, M. (1999) The Factors Related to Job Satisfaction and Professional Burnout in the Primary Care Physicians of Asturias. Atencion Primaria, 24, 352-359.

[14] Abushaikha, L. and Saca-Hazboun, H. (2009) Job Satisfaction and Burnout among Palestinian Nurses. Eastern Mediterranean Health Journal, 15, 190-197.

[15] Leither, M. and Maslach, C. (2009) Nurse Turnover: The Mediating Role of the Nursing Work Index. Journal of Nursing Management, 17, 331-339. http://dx.doi.org/10.1111/j.1365-2834.2009.01004.x

[16] Vahey, D., Aiken, L., Sloane, D., Clarke, S. and Vargas, D. (2004) Nurse Burnout and Patient Satisfaction. Medical Care, 42, II57-II66.

[17] Cimiotti, J., Aiken, L., Sloane, D. and Wu, E. (2012) Nurse Staffing, Burnout, and Health Care-Associated Infection. American Journal of Infection Control, 40, 486-490. http://dx.doi.org/10.1016/j.ajic.2012.02.029

[18] Laschinger, H., Grau, A., Finegan, J. and Wilk, P. (2010) New Graduate Nurses’ Experiences of Bullying and Burnout in Hospital Settings. Journal of Advanced Nursing, 66, 2732-2742. http://dx.doi.org/10.1111/j.1365-2648.2010.05420.x

[19] Laschinger, H. and Grau, A. (2012) The Influence of Personal Dispositional Factors and Organizational Resources on Workplace Violence, Burnout, and Health Outcomes in New Graduate Nurses: A Cross-Sectional Study. International Journal of Nursing Studies, 49, 282-291. http://dx.doi.org/10.1016/j.ijnurstu.2011.09.004

[20] Thompson, C., Dalgleish, L., Bucknall, T., Estabrooks, C., Hutchinson, A., Fraser, K., et al. (2008) The Effects of Time Pressure and Experience on Nurses’ Risk Assessment Decisions: A Signal Detection Analysis. Nursing Research, 57, 302-311. http://dx.doi.org/10.1097/01.NNR.0000313504.37970.f9

[21] Scott, L., Rogers, A., Hwang, W. and Zhang, Y. (2006) Effects of Critical Care Nurses’ Work Hours on Vigilance and Patients' Safety. American Journal of Critical Care, 15, 30-37.

[22] Teng, C., Hsiao, F. and Chou, T. (2010) Nurse-Perceived Time Pressure and Patient-Perceived Care Quality. Journal of Nursing Management, 18, 275-284. http://dx.doi.org/10.1111/j.1365-2834.2010.01073.x

[23] Josefsson, K. (2012) Registered Nurses’ Health in Community Elderly Care in Sweden. International Journal of Nursing, 59, 409-415.

[24] Darawad, M. (2011) An Examination of the Role Discrepancy and Turnover Intention among ICU Nurses at a Jordanian Teaching Hospital. Proceeding at the 3rd E-Health Conference in the Middle East, Dubai, February 2011, 102116.

[25] Hughes, F., Finlayson, M. and Firkin, P. (2005) Situational Analysis of 19 Island Countries in Relation to Mental Health Capability and Capacity. World Health Organization, Geneva.

[26] Mrayyan, M.T. (2007) Nursing Practice Problems in Private Hospitals in Jordan: Students' Perspectives. Nurse Education in Practice, 7, 82-87. http://dx.doi.org/10.1016/j.nepr.2006.04.007

[27] Alasad, J.A. and Ahmad, M.M. (2003) Patients' Satisfaction with Nursing Care in Jordan. International Journal of Health Care Quality Assurance, 16, 279-285. http://dx.doi.org/10.1108/09526860310495660

[28] Putrevu, S. and Ratchford, B. (1997) A Model of Search Behavior with an Application to Grocery Shopping. Journal of Retailing, 73, 463-486.

[29] Saleh, A., Darawad, M. and Al-Hussami, M. (2014) Organizational Commitment and Work Satisfaction among Jordanian Nurses: A Comparative Study. Life Science Journal, 11, 31-36.

[30] Bakker, A., Demerouti, E., Taris, T., Schaufeli, W. and Schreurs, P. (2003) A Multigroup Analysis of the Job Demands-Resources Model in Four Home Care Organizations. International Journal of Stress Management, 10, 16-38. http://dx.doi.org/10.1037/1072-5245.10.1.16

[31] Naruse, T., Taguchi, A., Kuwahara, Y., Nagata, S., Watai, I. and Murashima, S. (2012) Relationship between Per- 
ceived Time Pressure during Visits and Burnout among Home Visiting Nurses in Japan. Japan Journal of Nursing Science, 9, 185-194. http://dx.doi.org/10.1111/j.1742-7924.2011.00201.x

[32] Maslach, C., Jackson, S. and Leitner, M. (1996) Maslach Burnout Inventory Manual. 3rd Edition, Consulting Psychologists Press, Mountain View.

[33] Julliann, G. (2008) The Nurse Leader in the Community. In: Marcia, S. and Jeanette, L., Eds., Public Health Nursing, 7th Edition, Elsevier's Health Sciences Rights Department, Philadelphia, 941-949.

[34] Hooper, C., Craig, J., Janvrin, D., Wetsel, M. and Reimels, E. (2010) Compassion Satisfaction, Burnout, and Compassion Fatigue among Emergency Nurses Compared with Nurses in Other Selected Inpatient Specialties. Journal of Emergency Nursing, 36, 420-427. http://dx.doi.org/10.1016/j.jen.2009.11.027

[35] Duffield, C., Gardner, G. and Cartling-Paull, C. (2008) Nursing Work and the Use of Nursing Time. Journal of Clinical Nursing, 17, 3269-3274. http://dx.doi.org/10.1111/j.1365-2702.2008.02637.x

[36] Finfgeld-Connett, D. (2008) Meta-Synthesis of Caring in Nursing. Journal of Clinical Nursing, 17, $196-204$. 
Scientific Research Publishing (SCIRP) is one of the largest Open Access journal publishers. It is currently publishing more than 200 open access, online, peer-reviewed journals covering a wide range of academic disciplines. SCIRP serves the worldwide academic communities and contributes to the progress and application of science with its publication.

Other selected journals from SCIRP are listed as below. Submit your manuscript to us via either submit@scirp.org or Online Submission Portal.
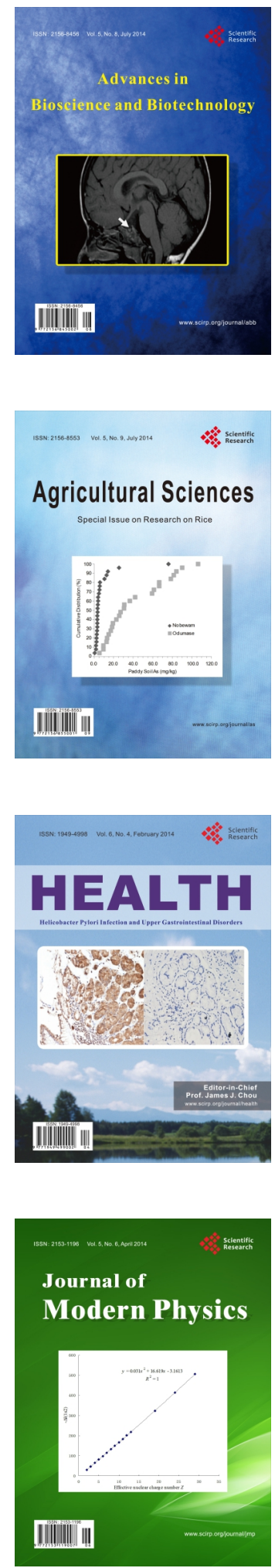
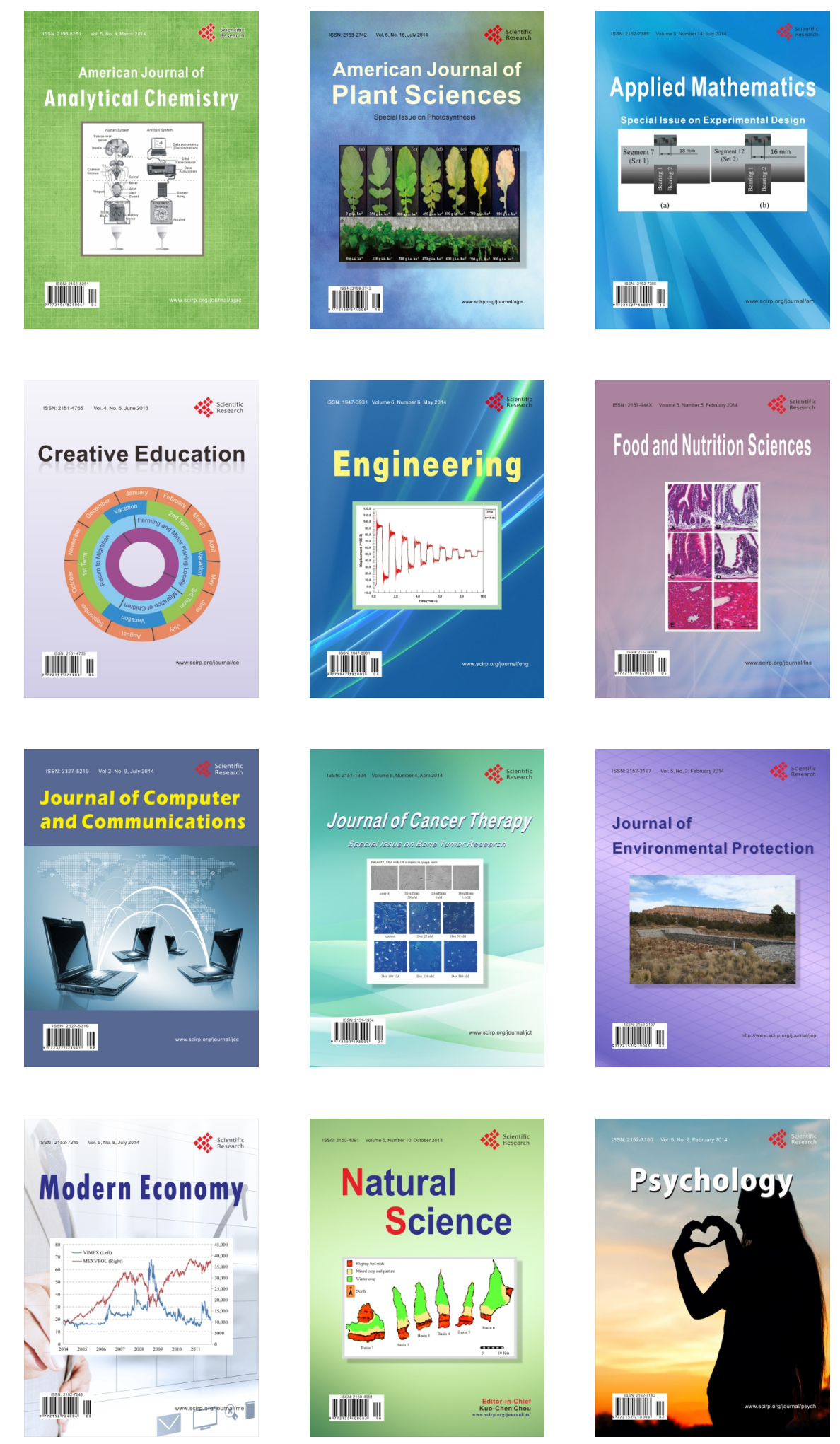